\title{
Design for Development: A Capability Approach Ilse Oosterlaken'
}

1 Department of Philosophy, Faculty of Technology, Policy and Management, Delft University of Technology/3TU. Centre for Ethics and Technology. This paper is a modification of the start document (E.T. Oosterlaken, May 26th of 2008, working paper of the 3TU.Centre for Ethics and Technology) for a research project that will be executed at TU Delft in the period 2008-2013.

2 Victor Margolin, “Design for Development: Towards a History," Design Studies 28 (2007): 111-115.

3 Dean Nieusma, "Alternative Design Scholarship: Working towards Appropriate Design," Design Issues 20 (2004): 13-24.

4 Angarad Thomas, "Design, Poverty, and Sustainable Development," Design Issues 22 (2006): 54-65.

5 Victor Margolin and Sylvia Margolin, "A 'Social Model' of Design: Issues of Practice and Research," Design Issues 18 (2002): 24-30.

6 Amartya Sen, Development as Freedom (New York: Anchor Books, 1999).

7 Richard Buchanan, "Human Dignity and Human Rights: Thoughts on the Principles of Human-Centered Desian." Design Issues 17:3 (2001): 35-39.

8 See among others: Martha C. Nussbaum, Women and Human Development: The Capability Approach (New York: Cambridge University Press, 2000).

9 Ingrid Robeyns, "The Capability Approach - A Theoretical Survev," Journal of Human Development 6:1 (2005): 94-114. Unless stated otherwise, this is the publication of Robeyns that I refer to.

10 Sabine Alkire, "Why the Capability Approach?" Journal of Human Development 6:1 (2005): 115-133. Unless stated otherwise, this is the publication of Alkire that I refer to.

\section{Introduction}

Experts seem to agree that in the past decades little scholarly attention has been paid in development and design scholarship to ethics and global justice issues. The subject is sometimes discussed under the heading of "design for development," "appropriate technology," ${ }^{\prime 3}$ or "design in a poor context, for the alleviation of poverty;"4 but hardly ever receives an in-depth treatment and exclusive attention. Margolin and Margolin, discussing socially responsible design in a broader sense (i.e., not only addressing the needs of the global poor, but also those of the aged, the disabled, etc.), note that there are "extremely well-developed" theories about "design for the market." On the contrary, "little thought has been given to the structures, methods, and objectives of social design. ${ }^{\prime 5}$ Yet the fact, alone, that several articles on this topic appeared in Design Issues in recent years is an indicator that this is starting to change.

In order to further advance this neglected area of design, I suggest a "capability approach" towards designing for society, and particularly, the world's poor. Central in this approach are human capabilities; the effective opportunities that people have to "live the lives that they have reason to value." ${ }^{6}$ Capabilities offer an alternative for human dignity and human rights as the grounds for, or first principle of, design as has been proposed by Buchanan; ${ }^{7}$ an alternative that may be more appealing at first sight for designers. I will first introduce the notion of the capability approach. Then I will explain its relevance for engineering and design before sketching some directions for future research on design for global justice.

\section{The Capability Approach}

The capability approach has been pioneered and developed by the economist and philosopher Amartya Sen and the philosopher Martha Nussbaum. ${ }^{8}$ According to this approach, the proper evaluative space in questions of justice, equality, and development is not income, not resources, not primary goods, not utility (i.e., happiness or the sum of pains and pleasures) or preference satisfaction. Its proponents argue that the focus should be on human capabilities. Capabilities have been described as "what people are effectively able to do and be," beings and doings."'10 These beings and doings are called "function- 
11 Ingrid Robeyns, "The Capability Approach - A Theoretical Survey."

12 Sabine Alkire, "Why the Capability Approach?"

13 Ingrid Robeyns, "The Capability Approach - A Theoretical Survey."

14 Sabina Alkire, "Capability and Functionings: Definition and Justification" in Briefing Notes (Human Development and Capability Association, www.hd-ca.org, last updated 1 September 2005).

15 Amartya Sen, "Justice: Means versus Freedoms," Philosophy and Public Affairs 19:2 (1990): 111-121.

16 Robeyns explains this very clearly, including a nice schematic representation of how the conversion of goods and services into functionings takes place.

ings" by Sen. Functionings "together constitute what makes a life valuable" ${ }^{11}$ and are "constitutive of a person's being." ${ }^{12}$ Examples of functionings are such diverse things as working, resting, being literate, being healthy, being part of a community, being able to travel, and being confident. "The distinction between achieved functionings and capabilities," as Robeyns explains, "is between the realized and the effectively possible; in other words, between achievements on the one hand, and freedoms or valuable options from which one can choose on the other."13 According to Alkire, one reason to focus on capabilities instead of functionings is that we value free choice:

A person who is fasting is in a state of undernutrition, which may seem very similar to a person who is starving. But in the one case, the fasting person could eat and chooses not to; whereas the starving person would eat if she could. ${ }^{14}$

Moreover, the capability approach recognizes the importance of both "well-being freedom" and "agency freedom." The latter acknowledges that people pursue not only their own well-being, but may also choose to pursue other ends; for example, the well-being of others, living up to religious ideals, or following moral norms.

Why should we focus on these capabilities in our developmental efforts, rather than utility or resources? One example often given in arguing for capabilities rather than resources is that a healthy and a handicapped person would need different amounts of resources to enable them to have the same opportunities in life. Also, for other reasons, the relationship between a certain amount of goods and what a person can do or can be varies according to Sen:

... a person may have more income and more nutritional intake than another person, but less freedom to live a wellnourished existence because of a higher basal metabolic rate, greater vulnerability to parasitic diseases, larger body size, or pregnancy. ${ }^{15}$

One of the crucial insights of the capability approach is that the conversion of goods and services into functionings is influenced by personal, social, and environmental conversion factors; and that it should not be taken for granted that resource provision leads to increased capabilities or functionings..$^{16}$

The reason why capability theorists prefer these capabilities over utility or preference satisfaction is the phenomenon which Sen has called "adaptive preferences":

Our desires and pleasure-taking abilities adjust to circumstances; especially to make life bearable in adverse situations. The utility calculus can be deeply unfair to those who are persistently deprived.... The deprived people tend to come to terms with their deprivation because of the sheer necessity of survival; and they may, as a result, lack the courage to demand any radical change, and may even 
adjust their desires and expectations to what they unambitiously see as feasible. ${ }^{17}$

The capability approach is increasingly being applied in different areas. In 2006, Robeyns identified nine different types of applications of the capability approach: “(1) general assessments of human development of countries, (2) assessing small-scale development projects, (3) identifying the poor in developing countries, (4) poverty and well-being assessment in advanced economies, (5) deprivation of disabled people, (6) assessing gender inequalities, (7) debating policies, (8) critiquing and assessing social norms, practices, and discourses, and (9) functionings and capabilities as concepts in nonnormative research" ${ }^{18}$ It has led to lively debates on several issues.

One very important debate is about which capabilities matter and who (how, when) is to decide this. Different visions exist on this issue. One of several differences that Robeyns mentions between the contributions of Nussbaum and Sen is that, "Whereas in Sen's work the notion of capabilities is primarily that of a real or effective opportunity (as in social choice theory); Nussbaum's notion of capability pays more attention to people's skills and personality traits as aspects of capabilities." And while Nussbaum comes up with a concrete and-so she believes-universally applicable list of important capabilities, "Sen has always refused to endorse one specific well-defined list of capabilities," or to set priorities among different capabilities. His reasons are that the proper list of capabilities may depend on purpose and context, and should be a result of public reasoning and democracy; not something a theorist should come up with.

The question of operationalization of this view has, understandably, received quite some attention. ${ }^{19}$ How do we expand the capabilities or positive freedoms of people, and how do we measure the results? "For some of these capabilities," says Robeyns, "the main input will be financial resources and economic production; but for others, it can also be political practices and institutions, ... political participation, social or cultural practices, social structures, social institutions, public goods, social norms, traditions and habits." Alkire argues that "operationalizing is not a one-time thing," but something that is dependent upon such things as country, level of action and the problem at hand. Both Robeyns and Alkire conceive of the capability approach as interdisciplinary. Alkire especially advocates close collaboration between capability theorists and experts in relevant fields of application; for example, nutritional science or econometrics, to "trace its implications all the way through." She does not mention engineering and design, but she easily could have, as will be explained in the next section. 
20 See, for example, Jeroen van den Hoven and Emma Rooksby, "Distributive Justice and the Value of Information: A (Broadly) Rawlsian Approach" in Information Technology and Moral Philosophy, edited by J. van den Hoven and J. Weckert (Cambridge: Cambridge University Press, 2008); Justine Johnstone, "Technology as Empowerment: A Capability Approach to Computer Ethics," Ethics and Information Technology 9 (2007): 73-87; Yingqin Zheng, "Exploring the Value of the Capability Approach for E-development" (paper presented at the 9th International Conference on Social Implications of Computers in Developing Countries, Sao Paulo, Brazil, 2007).

21 For example, in Robeyns (2005), "The Capability Approach"; and Alkire (2005) "Capability and Functionings."

22 Amartya Sen, "Poor, Relatively Speaking," Oxford Economic Papers (New Series) 35:2 (1983): 153-169.

\section{Technology as Capability Expansion}

From a common sense point of view, adopting the capability approach immediately seems to be strongly compatible with recognizing and improving the contribution of technology and engineering products to development. After all, what is technology for, if not increasing the capabilities that we have as human beings? Just as the wheel enhanced our capability to transport heavy loads; more recently, the computer enhanced our capabilities to make complex calculations. Technologies have grown more complex over time, and are in an increasingly complex way intertwined with society, institutions, laws, and procedures. But ideally, we still intend them to add to our capabilities to survive (such as in the case of medical equipment); and to participate in public deliberation (such as in the case of ICT/Internet applications that facilitate political discussion).

As obvious as making this connection between technology and capabilities may seem, philosophers working on the capability approach so far do not seem to have sufficiently realized the relevance of technology, engineering, and design for capability expansion. For example, it does not figure on the list that Robeyns presents of inputs for capabilities (political practices, social institutions, habits, etc.). It has hardly received any attention in the literature. Some explorative, agenda-setting articles appeared only recently; mainly concerned with ICT. ${ }^{20}$ Remarkably, a specific piece of technical equipment, namely a bicycle, has been used on several occasions to explain the approach: ${ }^{21}$

Take a bicycle.... Having a bike gives a person the ability to move about in a certain way that he may not be able to do without the bike. So the transportation characteristic of the bike gives the person the capability of moving in a certain way. That capability may give the person utility or happiness if he seeks such movement or finds it pleasurable. So there is, as it were, a sequence from a commodity (in this case, a bike), to characteristics (in this case, transportation), to capability to function (in this case, the ability to move), to utility (in this case, pleasure from moving)..$^{22}$

However, the bicycle is just used as an example in explaining the focus of the capability approach, and nothing more. Robeyns does say that the characteristics of the bicycle expand the owner's capability to move around. Yet she also states that:

We are not interested in a bicycle because it is an object made from certain materials with a specific shape and colour, but because it can take us to places where we want to go, and in a faster way than if we were walking. (The emphasis is mine.)

Of course, the point that Robeyns here attempts to make is that what matters in the end is capability expansion, and that the bicycle is only instrumentally important in this respect. 
23 Langdon Winner, "Do Artifacts Have Politics?" Daeddalus 109:1 (1980): 121-136; Bruno Latour, "Where Are the Missing Masses? The Sociology of a Few Mundane Artifacts" in Shaping Technology / Building Society, Wiebe E. Bijker and J. Law, eds. (Cambridge, MA: The MIT Press, 1992).

24 Jeroen van den Hoven, "ICT and Value Sensitive Design" in The Information Society: Innovations, Legitimacy, Ethics, and Democracy, P. Goujon, S. Lavelle, P. Duquenoy, K. Kimppa, and V. Laurent, eds. (Boston: Springer, 2007); Mary L. Cummings, "Integrating Ethics in Design through the Value-Sensitive Design Approach," Science and Engineering Ethics 12:4 (2006): 701-715.

25 Wiebe E. Bijker, Of Bicycles, Bakelites, and Bulbs: Toward a Theory of Sociotechnical Change (Cambridge, MA: The MIT Press, 1995).
However, Robeyns's remark is still naive regarding the sociology and philosophy of technology, as I will explain in the next section.

\section{The Significance of the Details of Design}

Philosophers and sociologists of technology have argued in the past decades that engineering products are far from neutral instruments to be used at will for either good or bad, but rather value-laden or inherently normative. ${ }^{23}$ Values such as privacy, autonomy, sustainability, safety, and justice can be realized in our technologies-or these could rather embed and create the opposite: injustice, insecurity, and so on. And many different design options are generally available during the development process of a new technology or product. This means that the details of design are morally significant. If technologies are value-laden and design features are relevant, we should—so it has been suggested—design these technologies in such a way that they incorporate our moral values. This thought has led to the emerging research field of so-called "value sensitive design," which initially was limited to R\&D in the area of ICT, but is now also gaining popularity in other engineering areas. ${ }^{24}$

Keeping this in mind, let us discuss the bicycle a bit further. Nowadays, we may take it for granted as a piece of equipment that "can take us to places where we want to go, and in a faster way than if we were walking," as Robeyns did. However, the bicycle is not such a simple and straightforward artifact as it may seem. As it happens, it figures in a classical case study in the sociology of technology. ${ }^{25}$ In this study, Bijker describes in detail how the development of the modern bike took place, stretching over a period of more than two centuries in which many different design varieties competed with each other. What is especially interesting is that Bijker's analysis has shown that different social groups attached different meanings to this new artifact, and that this influenced developments in its design. Initially, it was mainly viewed as a piece of sports equipment, used for racing contests. This means that the speed that a certain type of bicycle could achieve was very important. In the second half of the 19th century, the dominant model had become the so-called "highwheeled Ordinary bicycle," which had a very large front wheel in comparison to the smaller rear wheel, and pedals connected directly to the front wheel. Because of the way in which bicycles were viewed, it developed in a direction of less rather than more safety:

The trend of enlarging the front wheel of the velocipede had continued once speed had become so important, and this made it necessary to move the saddle forward in order to keep pedals within reach of the feet. This implied a reduction of the rear wheel's diameter- partly because otherwise the machine could not be mounted at all, partly to reduce the bicycle's weight, and partly for aesthetic reasons (it set off the grandeur of the high wheel). But these two developments moved the center of gravity of the 
bicycle and rider far forward, to a position almost directly above the turning point of the system. Thus, only a very small counter force-for example, from the bumpiness of the road, but also from the sudden applications of the brake-would topple the whole thing.

Because of the bad condition of the roads in those days, this happened quite frequently. However, this was not considered a problem, nor a sign of bad bicycle design. Cycling was considered to be an activity for young and adventurous men. The difficulty of riding the "Ordinary" and its accident proneness only contributed to the ability of these lads to impress the ladies by participating in cycling contests in the parks. "Falls were such an accepted part of bicycling," Bijker notes, "that producers advertised their bicycles' ability to withstand falls, rather than claiming that they did not fall at all."

Thus, bicycling was rarely undertaken by senior citizens or women, and certainly not considered as a form of transportation. This, says Bijker, only changed "when manufacturers began to regard women and older men as potential bicycle buyers." The realization that there was a business opportunity here led to a whole series of new developments in bicycle design, with safety instead of speed now being a prominent goal. Some design changes were successful; others not. These attempts to reach new target groups led in the end to the dominance of the so-called "safety bicycle," which is chain driven by the rear wheel. The main function of the bicycle had become transportation.

After this bicycle detour, let us return again to the concept of value-sensitive design. A similar perspective may thus be just what is needed if we want to introduce new technologies in developing countries in such a way that it does benefit the poor by expanding their human capabilities. If one is interested in making the introduction of a new technology, such as the bicycle in 19th century Europe, or currently ICT equipment in developing countries, contribute to capability expansion, one should also be interested in its design. As the bicycle example illustrates, the design features of technologies are relevant for their effect on human capabilities. Perhaps we should not care very much about the color of the bicycle-it is hard to imagine how this could be relevant-but shape and material definitely deserve our attention. (Although, I agree with Robeyns for instrumental reasons.) We should not too easily assume that a certain product or technology will do well in expanding people's capabilities. Sen's capability approach, I propose, should be directly applied to the design and engineering of these new technologies and products for developing countries. What responsible innovation for the benefit of the global poor requires, one may say, is "capability sensitive design" of technologies for developing countries. 


\section{Capability Sensitive Design}

A central question, of course, is what capability sensitive design entails, and whether or not adopting such a new design philosophy will in the end make a difference in the lives of people. This is something that needs further investigation, and the last section will point out some research directions. But first let me say something about why I expect that taking a capability approach is valuable for design scholarship and practice. In the introduction, I referred to an essay by Buchanan. He writes-and I will quote him quite extensive because of the importance and eloquence of his message-the following:

We tend to discuss the principles of form and composition, the principles of aesthetics, the principles of usability, the principles of market economics and business operations, or the mechanical and technological principles that underpin products. In short, we are better able to discuss the principles of the various methods that are employed in design thinking than the first principles of design, the principles on which our work is ultimately grounded and justified. The evidence of this is the great difficulty we have in discussing the ethical and political implications of design.... The implications of the idea that design is grounded in human dignity and human rights are enormous, and they deserve careful exploration. ${ }^{26}$

The grounding principle of design that Buchanan envisions is related to the one I am proposing. Sen himself has declared that human capabilities and human rights are closely connected concepts. For example, he says that "there are many human rights that can be seen as rights to particular capabilities" ${ }^{\prime 27}$ - because of the intuitively obvious connection between technology and engineering products on the one hand, and the expansion of human functionings and capabilities on the other-it will be easier for designers to incorporate and take into account human capabilities than to deal with human rights. As Johnstone phrased it:

Because the theory is essentially naturalistic and functionalist in orientation, capability analyses are able to integrate descriptive and normative dimensions in a way that is particularly appropriate to technological domains..$^{28}$

The effects of applying the capability approach to the domain of technology, engineering, and design may be huge. As Buchanan writes about "human-centered design":

Unfortunately, we often forget the full force and meaning of the phrase-and the first principle which it expresses. This happens, for example, when we reduce our considerations of human-centered design to matters of sheer usability and when we speak merely of "use-centered design." It is true that usability plays an important role in human-centered 
design, but the principles that guide our work are not exhausted when we have finished our ergonomic, psychological, sociological, and anthropological studies of what fits the human body and mind. ${ }^{29}$

The observation is still valid. Let's illustrate this with two examples. Chalmers University of Technology (Sweden) tells prospective industrial design engineering (IDE) students that "the degree to which a product satisfies customers and users is ... regarded as one of the most critical factors in product development." New developments mean that "previous values, such as functionality, reliability, and cost are partly to be complemented by, partly to be replaced by, other values, such as usability, comfort, aesthetics, pleasure, and excitement." ${ }^{30}$ One could argue that there are more fundamental values at stake in design than the ones mentioned here. Likewise, in a proposal for a new IDE research program, ${ }^{31}$ Delft University of Technology (The Netherlands) recently claimed that industrial design should contribute to the "well-being" of people, which is defined as "an experiential state of people and organizations, which can have many shapes, such as satisfaction, fulfillment, support and inspiration, protection, acknowledgement, comfort, happiness, and involvement." The words chosen by both universities (the emphasis is mine) suggest that it is currently preferences or utility rather than something such as human dignity or capabilities that are at the core of the work of many IDE departments (assuming that these examples are representative). Without denying the relevance of these notions, the concept of human capabilities offers a richer understanding of well-being: one that adds to design scholarship and practice. It certainly accommodates the ideas and preferences of design constituencies which include moral considerations concerning autonomy, privacy, sustainability, accountability, responsibility, etc., as well as the ones mentioned in the most common descriptions of the IDE communities.

What capability sensitive design as an alternative approach entails is a matter of further investigation. Yet we can easily deduct some rough pointers from the capability approach. One of the merits of the capability approach is that it has drawn attention to the existence of immense human diversity; not only in terms of what we value, but also in terms of personal and social/environmental characteristics that influence the conversion from resources into capabilities and functionings. People who have paralyzed legs, for example, will obviously not be able to ride an ordinary bicycle. In this case, a personal characteristic completely blocks the conversion of a resource into capability or functioning. One beauty of technological artifacts, however, is that they are resources whose properties can be moulded. They can-within certain limits—-be designed in such a way that they take these conversion factors into account. cultural, and economic context." This is mentioned, however, as a limiting condition. 
Whatever else it may entail, capability sensitive design takes human diversity into account.

\section{A Case: Tricycles for the Disabled in Ghana}

If we consider this aspect of capability sensitive design, the design of tricycles for the disabled in developing countries may be a nice illustration of what I have in mind. The disabled in developing countries have, as Van Boeijen ${ }^{32}$ notes, little opportunities "in education, (finding) work and participation in social life," or to shape their own life. She writes:

The possession of a tricycle can give a large number of them the possibility to travel.... A tricycle is a hand-operated vehicle that is propelled by means of a chain- or cranklever mechanism and is suitable for driving long distances, under bad road conditions, and for the transportation of goods. All over the world small workshops in developing countries produce these tricycles in many different designs. These tricycle designs need improvements: they are often uncomfortable for the user, not suitable for the local situation, and difficult to produce. Imported tricycles from Western countries are often too expensive and not suitable for use under the average conditions in developing countries. Usually, they also lack spare parts which makes repair difficult or impossible.

At least since the 1990s, if not earlier, industrial design engineers have-in different local contexts-been working on design improvements that address these problems. In this way, they contribute to the expansion of the capability to move for an otherwise socially marginalized group.

In a case in Ghana, a local metal workshop had to stop the production of tricycles due to a lack of financial support. A team of industrial design engineering students did extensive research into local circumstances, the metal workshop, the disabled, and other stakeholders in order to find an appropriate design solution. Their tricycle, for example, has been adjusted in such a way as to enable the handicapped to sell ice cream stored in a cooler in front of the tricycle. Disabled persons are thus enabled to act as street vendors. The financial side of the tricycle production and provision also has been taken care of; among others by getting a company involved whose products can be sold by street vendors. ${ }^{33}$ By increasing the income, opportunities, and self-respect of the handicapped in this manner, the tricycles now also contribute to capabilities other than mobility.

Capability sensitive design envisioned in this way bears strong resemblance to the familiar concept of "universal design." As Nieusma explained, this approach is all about "accounting for diversity." ${ }^{34}$ It should be noted that, on Nieusma's analysis, my 
35 Ibid.

36 Alex Apsan Frediani, Participatory Methods and the Capability Approach (briefing note of the Human Development and Capability Association, www. capabilityapproach.com/pubs/Briefing_ on_PM_and_CA2.pdf, accessed 14 November 2008).

37 He bases his argument on a work by Cleaver: Frances Cleaver, "Institutions, Agency, and the Limitations of Participatory Approaches to Development" in Participation: The New Tyranny? B. Cooke and U. Kothari, eds. (London: Zed Books, 2001). example of the tricycles in Ghana seems rather an example of the more limited accessibility movement, a predecessor of the universal design movement. It is in no way my intention, however, to make capability sensitive design only responsive to differences in physical abilities or to just one, specific user group at a time. Moreover, future research may reveal that capability sensitive design has many more sides to it than has been discussed so far.

\section{Participation in Design}

Another feature of the capability approach is that it attaches great importance to agency, free choice, and value judgments. As mentioned earlier, Sen deliberately refrains from specifying and prioritizing a complete capability list. Not surprisingly, public deliberation and participation have thus received attention in the capability literature. It is here that research on capability sensitive design can and should make a link with participatory design which, according to Nieusma, ${ }^{35}$ "has developed into a well-articulated, welljustified methodology for user participation in design processes" and is all about "coping with disagreements." He regrets, however, that "increasingly, participatory design methodologies are used to advance the goals of user-centered design without emphasizing the inclusion of marginalized perspectives in design processes." We are reminded here of Buchanan's reflections on the ultimate ends of design, and the contrast with the actual focus of IDE departments.

Interestingly, Frediani, ${ }^{36}$ in exploring the connections between the capability approach and participatory methods more broadly, notices something similar. In practice, participatory methods used in developmental cooperation often do not meet the expectations, being "sometimes used merely as a tool for achieving preset objectives" and not as a process for true empowerment and improvement of people's lives. He argues ${ }^{37}$ that "participatory methods need to be complemented by a theory that explores the nature of people's lives and the relations between the many dimensions of well-being." This theory, he says, should be comprehensive, but flexible and able to capture complex linkages between (aspects of) poverty, intervention, participation, and empowerment. He feels that the capability approach is able to offer exactly that. In my view, the capability approach may be able to offer the same revival to the ideals of participatory design.

Finally, I will try to identify some issues that definitely deserve our attention and that hopefully will lead to fruitful discussions about the ethics of design and, more specifically, the concept of capability sensitive design.

\section{Some Directions for Future Research}

Applying the capability approach to the broad domain of technology, engineering, and design will require research in a wide range of different questions and cases. Research should address issues rang- 
38 Johnstone (2007), "Technology as Empowerment."

39 Evan Selinger, "Does Microcredit 'Empower'? Reflections on the Grameen Bank Debate," Human Studies 31 (2008): 27-41.

40 Yingqin Zheng (2007), "Exploring the Value of the Capability Approach for E-development."

41 Coimbatore Krishna Prahalad, The Fortune at the Bottom of the Pyramid: Eradicating Poverty through Profits (Upper Saddle River, NJ: Wharton School Publishing, 2005). "BoP" refers to the base of the income pyramid, with four billion people living on less than $\$ 2$ a day. Crabtree has argued that the BoP debate is too focused on income poverty, and should rather take a capability perspective: Andrew Crabtree (2007), Evaluating the "Bottom of the Pyramid" from a Fundamental Capabilities Perspective (Copenhagen: Copenhagen Business School, CBDS Working Paper Series).

42 Angarad Thomas, "Design, Poverty, and Sustainable Development." ing from design methods to the social and ethical dilemmas that the designer will encounter along the way. More theoretical reflection should go hand-in-hand with case studies of design projects. Johnston $\mathrm{e}^{38}$ mentions four different focal points for future research into technology and human capabilities: (1) particular groups or individuals, (2) particular capabilities, (3) particular situations or context, or (4) particular interventions (technologies, artifacts). Case studies could primarily address one of these aspects or a combination of them. She discusses this in relation to ICT only. This is a domain in which a lot of design takes place, the outcome of which is relevant for people's capabilities. In a Western context, one could think of reassessing the debate on privacy and ICT applications in terms of how the latter affect capabilities to control personal information flows. In the context of developing countries, it has been pointed out independently both by Selinger and Zheng that the expectations of ICT for development are high, and that critical reflection is rare. ICT in its current form does not necessarily contribute to (for example) the empowerment of women in developing countries, ${ }^{39}$ and a capability approach could be helpful in avoiding the "pitfalls in e-development." 40

The sort of products that industrial design engineers are concerned with offer another domain for application. Again, the context could be Europe or the U.S. However, I would especially like to encourage a capability approach towards design for development, since both the need and the potential impact are high. Such research could, as inspired by the work of business scholar Prahalad, take place it in a business-like context. Prahalad has unleashed new enthusiasm and resources for development collaboration with his plea to the business world to come up with innovative products for the "Base of the Pyramid" (BoP). ${ }^{41}$ His hypothesis is that companies can make a profit while poverty gets alleviated. This perspective could lead to more financial sustainability and thus the long-term effectiveness of development efforts. The design of these innovative products, however, is underexposed in the BoP literature, as Thomas $^{42}$ has noted. Moreover, one should not too easily assume that the interests of the poor and of companies are always compatible. Ethical and social dilemmas are to be expected in such a context, in which - to use Margolin's terminology—design for the market and social design come together. There is a real challenge here.

How do we proceed with such research? First and foremost, there is a (largely empirical) question of which capabilities can be expanded (or perhaps unintentionally hampered) by new technology and products, and what engineers and designers (can) contribute to this. And how can philosophical reflection on the ultimate objectives of development, as offered by the capability approach, be translated in concrete design practice, including methods and tools? As mentioned in the previous section, another important questionperhaps even more so in a $\mathrm{BoP} /$ business context-is who should 
43 I would like to thank Jeroen van den Hoven for his very helpful feedback on earlier versions of this article, and for his support in starting up research on this topic. determine which capabilities and design solutions are relevant in a specific case, and what should happen in the case of disagreement or conflicts of interests.

Capability sensitive design is not something completely new or entirely different from existing "alternative design scholarships," as Nieusma calls it. As we have seen, there is a clear link with universal design and participatory design. But rather than making capability sensitive design redundant, I consider this a strength. It indicates that capability sensitive design is able to integrate lessons learned into a more comprehensive approach which offers a clear philosophical foundation of the ultimate ends of design; is connected to an expanding body of literature in philosophy and the social sciences; and-perhaps even more important-which can provide engineers and designers the inspiration that is needed to advance design for development. ${ }^{43}$ 